(1)

CrossMark

\section{Inhaled corticosteroid containing combinations and mortality in COPD}

\author{
To the Editor:
}

There is no solid evidence that any pharmacological treatment reduces mortality in chronic obstructive pulmonary disease (COPD). Two large trials with mortality as an efficacy outcome have been carried out testing a combination of a long-acting beta-agonist (LABA) and an inhaled corticosteroid (ICS) and in both, the reduction in mortality failed to reach statistical significance $[1,2]$. This could be seen as proof of absence of effect, but given that the TORCH trial [1] resulted in a hazard ratio (HR) of 0.825 (95\% CI 0.681-1.002; $\mathrm{p}=0.052$ ) for the comparison of combined fluticasone propionate and salmeterol with placebo, the interpretation may not be that simple. The other negative trial, the SUMMIT trial [2], only included patients with moderate COPD and increased risk of cardiovascular comorbidity.

By contrast, when mortality was studied as a safety outcome in severe and very severe COPD patients receiving salmeterol in combination with fluticasone propionate experienced fewer deaths than those receiving the long-acting muscarinic receptor antagonist (LAMA) tiotropium in the INSPIRE trial [3]. In the very recent, large IMPACT study, using a single inhaler in the three treatment arms, LiPSON et al. [4] reported a significant mortality reduction in COPD patients at high risk of exacerbations $(55 \%$ had $\geqslant 2$ moderate or severe exacerbations and $26 \%$ had $\geqslant 1$ severe exacerbation in the past year) treated with LABA/ICS or LABA/LAMA/ICS combinations compared to a dual LABA/LAMA combination. In both studies, the lower mortality was seen despite an increased risk of pneumonia in the ICS-containing arms.

To further explore the potential effect of ICS-containing combinations in a single inhaler on mortality, we performed a stratified safety pooled analysis of all fatal adverse events (AEs) comparing extrafine ICS-containing combinations versus ICS-free treatments in three recent 52-week studies conducted in patients with severe to very severe COPD at increased risk for exacerbations $(\geqslant 1$ moderate or severe exacerbation in the past year). These are currently the only long-term studies comparing the fixed combination of extrafine beclometasone dipropionate (BDP), formoterol fumarate (FF) and glycopyrronium $(G)$ to 1) extrafine BDP/FF [5], 2) tiotropium or extrafine BDP/FF+tiotropium in a separate inhaler [6], or 3) indacaterol/glycopyrronium bromide (IND/GB) [7]. We had full access to these data and included them in our analysis.

When comparing time to death from pooled data for all extrafine ICS-containing treatments versus ICS-free treatments there was a numerical, but not statistically significant, reduction in the risk of developing a fatal event (HR 0.71,95\% CI 0.50-1.02; $\mathrm{p}=0.066$ ) (table 1). This can be translated into a number needed to treat (NNT) of 121 patients treated for 1 year to prevent one death; calculation of NNT was based on the survival probability at 52 weeks in the control group from Kaplan-Meier analysis and on the hazard ratio [8]. A similar effect was seen when comparing only BDP/FF/G versus ICS-free treatments (table 1). In addition, we found no differences between treatments for respiratory fatal events (HR 1.01, 95\% CI $0.45-2.22 ; \mathrm{p}=0.989)$. In contrast, we found that the risk of non-respiratory fatal events was significantly reduced with extrafine ICS-containing treatments versus ICS-free treatments (HR: 0.65, 95\% CI: $0.43-0.97, \mathrm{p}=0.037$ ) (table 1); i.e., a NNT of 120 patients treated for 1 year to prevent one death from non-respiratory causes.

Albeit nonstatistically significant, our findings could suggest that extrafine ICS-containing medications may be associated with a lower mortality in symptomatic COPD patients at risk for exacerbations compared with ICS-free treatments. Interestingly, the only statistically significant effect is on death due to non-respiratory causes, suggesting that a more intense therapy containing an ICS may have a direct or indirect effect on the several and relevant chronic diseases that almost invariably are associated with particularly severe

@ERSpublications

Combinations containing inhaled corticosteroids may reduce mortality in patients with COPD http://ow.ly/6UCy30lpwEi

Cite this article as: Vestbo J, Fabbri L, Papi A, et al. Inhaled corticosteroid containing combinations and mortality in COPD. Eur Respir J 2018; 52: 1801230 [https://doi.org/10.1183/13993003.01230-2018]. 
TABLE 1 Patients with fatal events and hazard ratios for the treatment group comparisons in TRILOGY [5], TRINITY [6] and TRIBUTE [7]

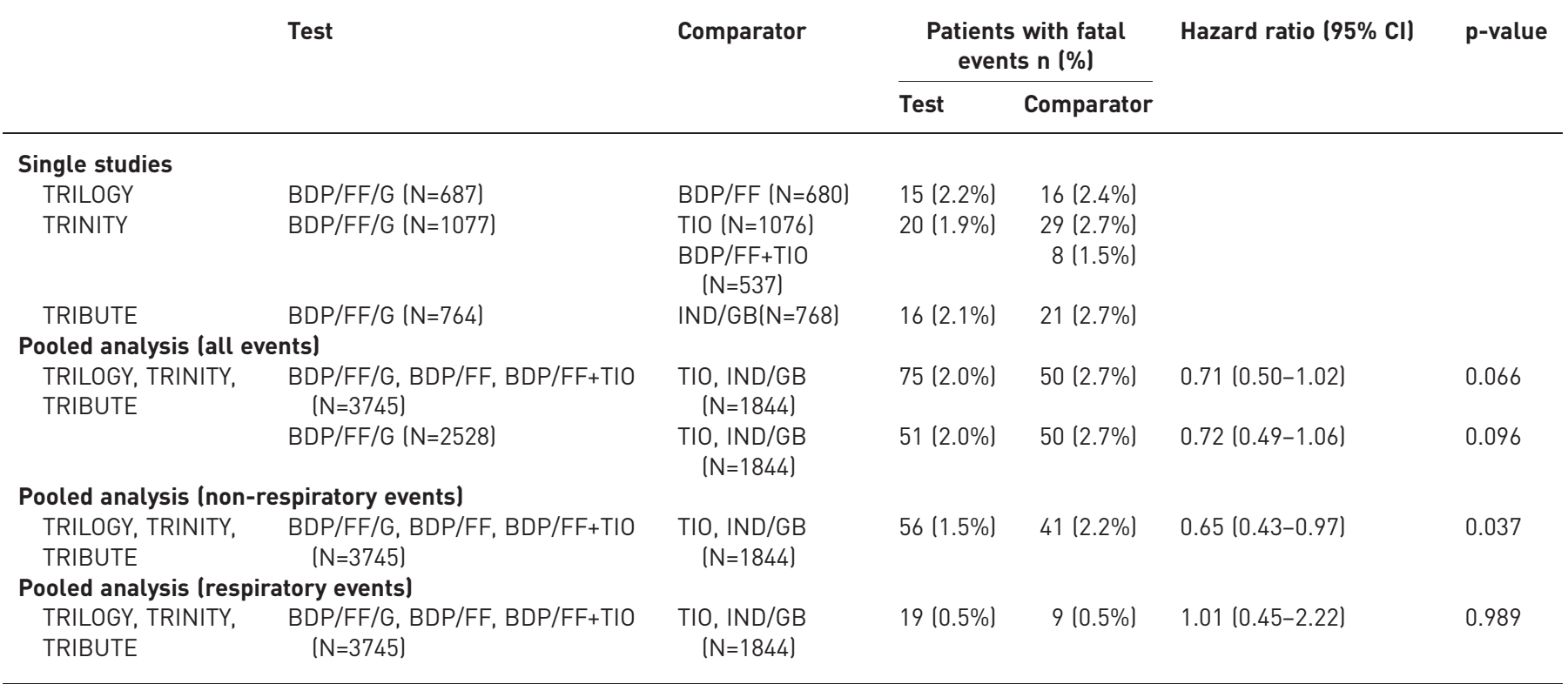

BDP: beclometasone dipropionate; FF: formoterol fumarate; G: glycopyrronium; TIO: tiotropium; IND: indacaterol; GB: glycopyrronium bromide.

symptomatic COPD [9]. This could be due to cardiovascular events being less likely if the underlying COPD is more stable; indirect evidence for this comes from studies showing a close link between exacerbations and acute coronary events $[10,11]$. It is also in line with the results of recent managed care studies suggesting that treating COPD and concomitant chronic diseases may improve survival [12].

Our analysis has limitations. It is not trivial whether mortality is an efficacy outcome or a safety outcome. In mortality studies, the aim is always to have complete follow-up of all patients to ensure their vital status at the end of the study. By contrast, adverse events were followed up for only 2 weeks after the last study drug intake. Thus, we cannot preclude that the effect seen is biased by this incomplete follow-up. In addition, there was no adjudication of cause of death in any of the studies included in this analysis.

Nevertheless, given the unidirectional effects seen in this analysis and the four previously cited studies [1-4], there may be cause for more optimism regarding the effect of more intense ICS-containing treatments on survival in symptomatic severe and very severe COPD patients, particularly considering that combination therapy, and especially triple therapy, is almost invariably required in these patients either to improve symptoms or quality of life, and/or to reduce exacerbations and hospitalisations. Of course, a properly designed and powered new study with mortality as the primary outcome in these patients is required for this optimism to be confirmed.

Jørgen Vestbo ${ }^{1,2}$, Leonardo Fabbri $\oplus^{3,4}$, Alberto Papi $\oplus^{3,5}$, Stefano Petruzzelli ${ }^{6}$, Mario Scuri ${ }^{6}$, Alessandro Guasconi ${ }^{6}$, Stefano Vezzoli ${ }^{6}$ and Dave Singh $^{1,7}$

${ }^{1}$ Division of Infection, Immunity and Respiratory Medicine, School of Biological Sciences, University of Manchester, Manchester Academic Health Science Centre, Manchester, UK. ${ }^{2}$ Manchester University NHS Foundation Trust, Manchester, UK. ${ }^{3}$ Dept of Medicine, University of Ferrara, Ferrara, Italy. ${ }^{4}$ COPD Center, Sahlgrenska University Hospital, Gothenburg, Sweden. ${ }^{5}$ Research Centre on Asthma and COPD, University of Ferrara, Ferrara, Italy. ${ }^{6}$ Global Clinical Development, Chiesi Farmaceutici SpA, Parma, Italy. ${ }^{7}$ Medicines Evaluation Unit, Manchester, UK.

Correspondence: Jørgen Vestbo, 2nd Floor, ERC Building, Wythenshawe Hospital, Southmoor Road, Manchester, M23 9LT, UK. E-mail: jorgen.vestbo@manchester.ac.uk

Received: July 022018 | Accepted after revision: Aug 082018

This study is registered at ClinicalTrials.gov with identifier numbers NCT01917331, NCT01911364 and NCT02579850. These trials, all terminated and reported, have no data sharing plan.

Conflict of interest: J. Vestbo reports personal fees (consultancy for COPD phase 2 and 3 programme and payment for lectures including service in speaker bureau) from GlaxoSmithKline, Chiesi Pharmaceuticals, Boehringer-Ingelheim, 
Novartis, and AstraZeneca, all outside the submitted work. L. Fabbri reports grants for research, personal fees and non-financial support (paid lectures, advisory board and travel expenses reimbursement) from Boehringer Ingelheim, Chiesi Farmaceutici, GlaxoSmithKline, Merck Sharp \& Dohme, Takeda, AstraZeneca, Novartis, Menarini, Laboratori Guidotti and Almirall, personal fees and non-financial support (paid lectures, advisory board and travel expenses reimbursement) from Pearl Therapeutics, Mundipharma and Boston Scientific, personal fees (paid lectures) from Kyorin and Bayer, personal fees from Zambon (paid lectures, advisory board and travel expenses reimbursement, grant for research), and grants from Pfizer, Dompè, Malesci, Biofutura Italia and Vree Health Italia, all outside the submitted work. A. Papi reports grants and personal fees from Chiesi Pharmaceuticals, during the conduct of the study; grants, personal fees, non-financial support and other (board membership, consultancy, payment for lectures, grants for research, travel expenses reimbursement) from Chiesi, Astrazeneca, GlaxoSmithKline, Boehringer Ingelheim, Pfizer, Mundipharma and TEVA, personal fees and non-financial support (payment for lectures, travel expenses reimbursement) from Menarini, Novartis and Zambon, all outside the submitted work. S. Petruzzelli has nothing to disclose. M. Scuri is a full-time employee of Chiesi Farmaceutici S.p.A. A. Guasconi is an employee of Chiesi Farmaceutici S.p.A. S. Vezzoli is an employee of Chiesi Farmaceutici SpA, the sponsor of the studies. D. Singh reports personal fees from Chiesi, during the conduct of the study; personal fees from Apellis, Cipla, Genentech, Peptinnovate and Skyepharma, grants and personal fees from AstraZeneca, Boehringer Ingleheim, Chiesi, GlaxoSmithKline, Glenmark, Menarini, Merck, Mundipharma, Novartis, Pfizer, Pulmatrix, Teva, Therevance and Verona, all outside the submitted work.

Support statement: This study was funded by Chiesi Farmaceutici. Funding information for this article has been deposited with the Crossref Funder Registry.

\section{References}

1 Calverley PM, Anderson JA, Celli B, et al. Salmeterol and fluticasone propionate and survival in chronic obstructive pulmonary disease. N Engl J Med 2007; 356: 775-789.

2 Vestbo J, Anderson JA, Brook RD, et al. Fluticasone furoate and vilanterol and survival in chronic obstructive pulmonary disease with heightened cardiovascular risk (SUMMIT): a double-blind randomised controlled trial. Lancet 2016; 387: 1817-1826.

3 Wedzicha JA, Calverley PMA, Seemungal TA, et al. The prevention of chronic obstructive pulmonary disease exacerbations by salmeterol/fluticasone propionate or tiotropium bromide. Am J Respir Crit Care Med 2008; 177: $19-26$.

4 Lipson DA, Barnhart F, Brealey N, et al. Once-daily single-inhaler triple versus dual therapy in patients with COPD. N Engl J Med 2018; 378: 1671-1680.

5 Singh D, Papi A, Corradi M, et al. Single inhaler triple therapy versus inhaled corticosteroid plus long-acting $\beta 2$-agonist therapy for chronic obstructive pulmonary disease (TRILOGY): a double-blind, parallel group, randomised controlled trial. Lancet 2016; 388: 963-973.

6 Vestbo J, Papi A, Corradi M, et al. Single inhaler extrafine triple therapy versus long-acting muscarinic antagonist therapy for chronic obstructive pulmonary disease (TRINITY): a double-blind, parallel group, randomized controlled trial. Lancet 2017; 389: 1919-1929.

7 Papi A, Vestbo J, Fabbri L, et al. Extrafine inhaled triple therapy versus dual bronchodilator therapy in chronic obstructive pulmonary disease (TRIBUTE): a double-blind, parallel group, randomised controlled trial. Lancet 2018; 391: 1076-1084.

8 Altman DG, Andersen PK. Calculating the number needed to treat for trials where the outcome is time to an event. BMJ 1999; 319: 1492-1495.

9 Vanfleteren LEGW, Spruit MA, Wouters EFM, et al. Management of chronic obstructive pulmonary disease beyond the lungs. Lancet Respir Med 2016; 11: 911-924.

10 Donaldson GC, Hurst JR, Smith CJ, et al. Increased risk of myocardial infarction and stroke following exacerbation of COPD. Chest 2010; 137: 1091-1097.

11 Kunisaki KM, Dransfield MT, Anderson JA, et al. Exacerbations of chronic obstructive pulmonary disease and cardiac events: a cohort analysis. Am J Respir Crit Care Med 2018; 198: 51-57.

12 Vanfleteren LEGW, Ullman A, Fabbri LM. Time for a longer and better life for patients with COPD. Eur Respir J 2018; 51: 1702569 . 